\title{
Carbohydrates, fats, and atherosclerosis
}

\author{
IAN MACDONALD
}

The relationship of diet to atherosclerosis is uncertain since many of the current theories, though supported by circumstantial evidence, lack absolute proof. One reason is that no satisfactory measure can be made of the diseased state that is being associated with the diet so that circuitous methods are necessary. Another reason for the difficulty in assessing the role of dietary components in causing atherosclerosis is the probability that atherosclerosis does not have a single aetiology, and that other variables, such as heredity, smoking, hypertension, and exercise, tend to obscure the effects of diet. Furthermore, accurate assessment of the diet is not easy, especially since the influential period of the diet may have been in childhood or early adulthood. Finally, most assessments of the role of the diet in atherosclerosis have been based on the high degree of association between raised serum lipid levels and one of the complications of atherosclerosis, especially coronary thrombosis. There is no conclusive proof that reduction of the raised lipid levels prevents or delays atherosclerosis but the evidence supporting this inference is impressive.

EVIDENCE THAT DIET IS RELATED TO ATHEROSCLEROSIS

Some components of the diet are known to raise the level of cholesterol and triglycerides in the blood and for this reason it is assumed that dietary components are involved in atherosclerosis.

Epidemiological studies show that an increase in the consumption of certain dietary constituents is directly related to an increased incidence of coronary thrombosis. This is a dangerous line of reasoning as there is probably a similar association between the incidence of coronary thrombosis and the number of baths installed or taken.

Certain peoples of the world have a very low incidence of heart disease and their diet differs from those peoples whose incidence is high. Indigenous Japanese have a very low incidence of coronary thrombosis, but when they move to Hawaii or the USA their incidence of the disease is the same as that of the local residents (Keys, Kimura, Kusukawa, Bronte-Stewart, Larsen, and Keys, 1958). This argument carries some force but is not entirely valid because factors other than diet, such as exercise and stress, may have changed.
Some recent prospective dietary studies have provided strong support for the view that the diet does play a role in the aetiology of one of the sequels of atherosclerosis, namely, coronary thrombosis.

DIETARY STUDIES The first of these studies was conducted by the so-called Anti-coronary Club of New York (Christakis, Rinzler, Archer, Winslow, Jampel, Stephenson, Friedman, Fein, Kraus, and James, 1966). One of two matched groups of middleaged men was advised to take a diet whose fat content was reduced and contained a high proportion of polyunsaturated fat. The other group received no dietary advice but were subjected to the same routine examinations as the test group. The serum cholesterol level of the test group fell significantly and their incidence of myocardial infarction was also less than that of the control group. This study, though not ideal, provides evidence compatible with the view that diet does play a part in the developmen of atherosclerosis.

A more extensive study, lasting over six years and involving two mental hospitals in Finland, has recently been reported (Turpeinen, Miettinen, Karvonen, Roine, Pekkarinen, Lehtosuo, and Alivirta, 1968). In one hospital the diet was changed so that most of the milk fat was replaced by soyabean oil, whereas in the other, kept as the control, there was no dietary change. On the experimental diet it was found that the serum cholesterol concentration fell by a mean of $50 \mathrm{mg} / 100 \mathrm{ml}$ in the male patients aged 34 to 64 years and that the incidence of coronary disease assessed on the basis of both electrocardiographic changes and coronary mortality was significantly lower.

Some prospective dietary experiments in patients who have had a myocardial infarct have also been reported recently (Leren, 1966; MRC, 1968). The conclusions drawn by the authors of these papers seem, to some extent, to conflict. It is possible that those with the most severe atherosclerosis died from their infarct and were thus selectively excluded from the trials.

\section{DIETARY FATTY ACIDS}

Much importance has been attached to dietary fat as the causation of coronary thrombosis. 
It is some years now since it was established that the substitution of vegetable fat for animal fat in the diet resulted in a reduction of the level of serum cholesterol (Kinsell, Partridge, Boling, Margen, and Michaels, 1952). Though the evidence that animal fat is a potent factor in the causation of atheroma and coronary artery disease is not conclusive, it is nevertheless sufficiently circumstantial for the American Heart Association to issue a warning to the public (1964) that at least half of the fat intake of the US citizen should be unsaturated or of vegetable origin, and furthermore, that the total fat intake should be reduced.

\section{DIETARY CHOLESTEROL}

The concentration of serum cholesterol can be reduced considerably by the use of a cholesterol-free diet. There seams to be a relationship between the amount of cholesterol in the diet and the level of serum cholesterol (Connor, Stone, and Hodges, 1964) so that the latter falls if the consumption of eggs and oysters is reduced. A low cholesterol diet is, however, very unappetizing.

Another sterol that has been reported to be active in reducing serum cholesterol is sitosterol (Beveridge, Haust, and Connell, 1964). In short-term experiments with diets containing large quantities of saturated fats, $\beta$-sitosterol was very effective in lowering the serum cholesterol, probably due to increased excretion of cholesterol in the faeces. Unfortunately there are no long-term studies to show that the dose of $\beta$-sitosterol given (approximately $0.5 \mathrm{~g} / 1,000$ calories) would be effective in maintaining a lower serum cholesterol level.

On 3 May 1968 the collective medical boards of the Scandinavian countries released a statement to the public which contained the following remarks: 'Cutting down on the total consumption of fat in combination with a reduction in the amount of saturated fats and a relative increase in the quantity of polyunsaturated fats can diminish the risk of atherosclerosis' and 'The consumption of vegetables, fruit, potatoes, skimmed milk, fish, lean meat, and cereal products should be increased.'

\section{DIETARY CARBOHYDRATES}

Carbohydrates in the form of simple sugars are appetizing as well as satisfying, and a dietary survey in the USA (Antar, Ohlson, and Hodges, 1964) has shown that, though the proportion of carbohydrate eaten in that country is little changed compared with the beginning of the century, the type of carbohydrate eaten has changed. Nowadays in the western world much of the dietary carbohydrate consists of simple di- or mono-saccharides rather than the complex starches.

In 1961 it was postulated that there are two kinds of hyperlipidaemia in man (Ahrens, Hirsch, Oettle, Farquhar, and Stein, 1961), one being fat-induced and the other carbohydrate-induced. In the same year a paper had been published stating that a low fat: high carbohydrate diet for 39 weeks resulted in an immediate rise in fasting serum glycerides, the peak level being at five weeks, followed by a gradual lowering of the level (Antonis and Bersohn, 1961). Many similar reports have appeared and carbohydrate-induced hyperglyceridaemia seems to be not uncommon.

Not many years ago it was thought that all dietary carbohydrates were converted to glucose and that it did not matter what type was eaten. This is now known not to be so, and, in view of the association between serum lipids and coronary thrombosis, it would be of interest to learn whether the lipid changes brought about by the modern tendency to consume simple carbohydrates were in the direction of those associated with coronary disease (Kuo, 1968). It has been suggested that the increased incidence of myocardial infarction is due to an increased sucrose intake (Yudkin, 1957) but the evidence for this is not clear-cut (Paul, Macmillan, McKean, and Park, 1968).

Women below menopausal age are much less likely to show symptoms or signs of atherosclerosis than men of the same age and it is interesting to note that in premenopausal women fructose fails to produce the rise in serum glycerides which occurs in men and postmenopausal women (Macdonald, 1966). There also seems to be a correlation between the concentration of fasting serum triglycerides and fructose tolerance in men but not in premenopausal women (Crossley, 1967). Another pointer suggesting that fructose may be more readily involved than glucose in triglyceride metabolism is the increased specific activity found in serum triglycerides after the ingestion of $\left[{ }^{14} \mathrm{C}\right]$ fructose as compared with $\left[{ }^{14} \mathrm{C}\right]$ glucose (Macdonald, 1969).

THE COMBINATION OF FATS WITH CARBOHYDRATES

The combination of certain dietary fats with certain dietary carbohydrates may be more atherogenic than the sum of the two when given alone. Conversely the combination of a certain carbohydrate with a certain fat may prevent the undesirable feature found when either substance is given alone. There is little evidence to support these possibilities, but it has been found that the increase in fasting serum triglyceride level found when sucrose is 
TABLE I

SERUM FINDINGS IN VARIOUS TYPES OF HYPERLIPOPROTEINAEMIA AFTER A 12-HOUR FAST (MODIFIED FROM FREDRICKSON et al, 1967)

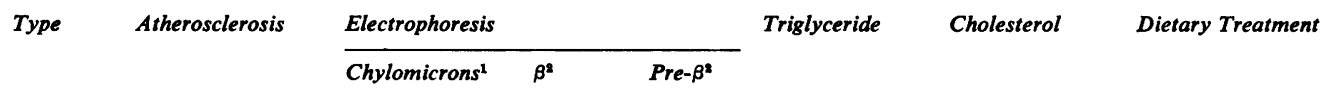

\begin{tabular}{|c|c|c|c|c|c|c|c|}
\hline I & Uncommon & $+t+$ & & & $+t+$ & & $<25 \mathrm{~g}$ fat $/$ day \\
\hline II & Accelerated & & +++ & & & +++ & $\begin{array}{l}\text { Low cholesterol } \\
\text { Polyunsaturated fats }\end{array}$ \\
\hline III & Accelerated & & ++ & + & + & ++ & As II \\
\hline IV & $\begin{array}{l}\text { Frequently } \\
\text { associated }\end{array}$ & & & +++ & $+t+$ & \pm & $<120$ g carbohydrate/day \\
\hline $\mathbf{V}$ & Not common & + & & $+t$ & ++ & + & $\begin{array}{l}\text { Moderate levels of carbohydrate } \\
\text { and fat }\end{array}$ \\
\hline
\end{tabular}

${ }^{1}$ Chylomicrons, ie, particles of exogenous fat which remain at the origin ${ }^{2} . \beta$ and pre- $\beta$ refer to lipoproteins (as revealed by fat stains) which travel with or just ahead of $\beta$-globulins.

given either alone or with cream is absent when sucrose is given with a polyunsaturated fat (Macdonald, 1967). The metabolic interrelationship between the various foods we eat is a relatively unexplored region and is probably of greater potential importance to our well-being than the lack of interest suggests.

Not only what we eat but how we eat it seems to be of some importance in determining the metabolic responses to the constituents of the diet. Ischaemic heart disease is commoner among those who take three meals or less per day than among those who take five meals or more per day (Fabry, Fodor, Hejl, Geizerova, and Balcarova, 1968).

\section{INDIVIDUAL SUSCEPTIBILITY TO DIETARY CARBO- HYDRATES AND FATS}

It would be useful to know whether a person is unduly susceptible to either fat or carbohydrate, or both, in the diet. With this knowledge it should be possible to advise that person on his dietary habits so that the concentration of some of his fasting serum lipids could be lowered in the hope of reducing, if not atherosclerosis, then at least his chances of getting one of its complications. Last year a detailed and thoroughly practical account was given of the various types of hyperlipoproteinaemias and their relationship to fats and carbohydrates (Fredrickson, Levy, and Lees, 1967). It is, therefore, now possible to identify the type of serum lipid abnormality and to advise the patient accordingly (Table I).

Thus it seems that at the moment there is no entirely conclusive evidence that dietary fats or carbohydrates play a role in atherosclerosis. The evidence that points in this direction is, however, strong and it would probably be wise at this stage to accept the inference of this evidence and to give dietary advice accordingly. To decide what kind of hyperlipidaemia is present is a very useful guide to dietary treatment, and perhaps we may hope that means can be found whereby dietary adjustments can be made in susceptible persons early in life and thereby prevent the disease.

\section{REFERENCES}

Ahrens, E. H., Jr., Hirsch, J., Oette, K., Farquhar, J. W., ande Stein, Y. (1961). Trans. Ass. Amer. Phycns, 74, 134.

Antar, M. A., Ohlson, M. A., and Hodges, R. E. (1964), Amer. $J$. clin. Nutr., 14, 169.

Antonis, A., and Bersohn, I. (1961). Lancet, 1, 3.

Beveridge, J. M. R., Haust, H. L., and Connell, W. F. (1964). J. Nutr., 83, 119.

Christakis, G., Rinzler, S. H., Archer, M., Winslow, G., Jampel, S., Stephenson, J., Friedman, G., Fein, H., Kraus, A., and James, G. (1966). Amer. J. publ. Hlth, 56, 299.

Connor, W. E., Stone, D. B., and Hodges, R. E. (1964). J. clin. Invest., 43, 1691 .

Crossley, J. N. (1967). Proc. nutr. Soc., 26, iii.

Fábry, P., Fodor, J., Hejl, Z., Geizerová, H., and Balcarová, O. (1968), Lancet, 2, 190.

Fredrickson, D. S., Levy, R. I., and Lees, R. S. (1967). New Engl. J. Med., 276, 34, 94, 148, 215, and 273.

Keys, A., Kimura, N., Kusukawa, A., Bronte-Stewart, B., Larsen, N. and Keys, M. H. (1958). Ann, intern. Med., 48, 83.

Kinsell, L. W., Partridge, J., Boling, L., Margen, S., and Michaels, G. (1952). J. clin. Endocr., 12, 909.

Kuo, P. T. (1968). Ann. intern. Med., 68, 449.

Leren, P. (1966). Acta med. scand., suppl. 466.

Macdonald, I. (1966). Amer. J. clin. Nutr., 18, 369.

- (1967). Ibid., 20, 345.

(1969). Ibid., 21, 1366

M.R.C. Report (1968). Lancet, 2, 693.

Paul, O., Macmillan, A., McKean, H., and Park, H. (1968). Ibid., 2, 1049.

Turpeinen, O., Miettinen, M., Karvonen, M. J., Roine, P., Pekkarinen, M., Lehtosuo, E. J., and Alivirta, P. (1968). Amer. J. clin. Nutr., 21, 255.

Yudkin. J. (1957). Lancet, 2, 155 